\title{
Hatay ili turunçgillerinde zararlı Turunçgil ipek beyazsineği, Paraleyrodes minei laccarino (Hemiptera: Aleyrodidae)'nin konukçuları, popülasyon değişimi ve biyolojisi
}

Host plants, seasonal population fluctuations and biology of the Citrus nesting whitefly, Paraleyrodes minei laccarino (Hemiptera: Aleyrodidae) in Hatay province, Turkey

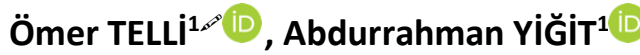

${ }^{1}$ Mustafa Kemal University, Department of Plant Protection, Faculty of Agriculture, Antakya, Hatay, Turkey.

MAKALE BILGISI / ARTICLE INFO

Makale tarihçesi / Article history:

DOI: $10.37908 / \mathrm{mkutbd} .599235$

Geliş tarihi /Received: 31.07 .2019

Kabul tarihi/Accepted: 23.01.2020

\section{Keywords:}

The Citrus nesting whitefly, Paraleyrodes minei, Turkey, citrus.

\footnotetext{
Corresponding author: Ömer TELLi

凶: omtelli@hotmail.com
}

ÖZET / A B STR A C T

Atıf / Citation: Telli Ö, Yiğit A (2020) Hatay ili turunçgillerinde zararlı Turunçgil ipek beyazsineği, Paraleyrodes minei laccarino (Hemiptera: Aleyrodidae)'nin konukçuları, popülasyon değişimi ve biyolojisi. MKU. Tar. Bil. Derg. 25(1) : 3645. DOI: $10.37908 /$ mkutbd.599235

\begin{abstract}
Aims: Studies were carried out on biology, host plants and seasonal population fluctuations of the Citrus nesting whitefly, Paraleyrodes minei laccarino (Hemiptera: Aleyrodidae) during the years of 2005-2006 in Hatay province, Turkey.

Methods and Results: Pupae and/or pupae molt were searched under the leaves for host plants of $P$. minei. Seasonal population fluctuations of $P$. minei in a 15 years old mandarin orchard, cv. "Satsuma" in Dörtyol (Hatay), during the years of 2005-2006. Studies on biology of $P$. minei was carried out under both laboratory and field conditions.

Paraleyrodes minei was spread to Dörtyol, Samandağ and İskenderun districts of Hatay. Apart from Citrus spp., Solanum melongena L., Laurus nobilis L., Punica granatum L., Diospyros kaki L., Hibiscus rosa-sinensis L. and Morus sp. were found as host plants for $P$. minei.

It was concluded that $P$. minei could be sampled from every part of a tree. Larvae and pupae populations of $P$. minei were increased in early-July, and then its populations were decreased remainder of the year, inconsequence of activity of the natural enemies, such as Conwentzia sp., Chrysoperla carnea Stephens (Neuroptera: Chrysopidae), Encarsia hispida DeSantis (Hymenoptera: Aphelinidae), Clitostethus arcuatus Risso, Chilocorus bipustulatus L. (Coleoptera: Coccinellidae) and entomopathogenic fungi, Cladosporium sp. (Moniliales: Dematiaceae). It was revealed that $P$. minei has 8 generations per year under field conditions. Developmental time from egg to adult for $P$. minei was avg. of $27,88(24-29)$ and $29,96(27-35)$ days under laboratory $\left(25 \pm 2^{\circ} \mathrm{C}, 70-80 \%\right.$ $\mathrm{RH}$ and 16 hours light/day), and field conditions, respectively.

Conclusions: The whitefly could be spread to all citrus plantations of Hatay. $P$. minei could be sampled from every part of a tree. Its high populations were observed on mature citrus leaves. It was also observed that $P$. minei populations could be suppressed by its natural enemies.

Significance and Impact of the Study: Paraleyrodes minei has a potential to reach the high densities under the suitable climatic conditions and absence of the natural enemies which cause significant crop losses and quality. All the agricultural practices should be manipulated regarding the integrated pest control approach for existence of the natural enemies in the citrus-ecosystem and applications of broad spectrum pesticides should be avoided.
\end{abstract}




\section{GíRiş}

Turunçgillerde yaklaşık olarak 65'in üzerinde zararlı beyazsinek (Hemiptera: Aleyrodidae) türü bilinmekle birlikte, bunlardan 15 kadarının dünyanın değişik turunçgil bölgelerinde ekonomik önemde zararlı olduğu bildirilmektedir (Mound ve Halsey, 1978). Hatay ilinin de yer aldığı Doğu Akdeniz Bölgesi'nde turunçgillerde görülen Turunçgil beyazsineği, Dialeurodes citri (Ashm.) ve Defne beyazsineği, Parabemisia myricae Kuwana (Hemiptera: Aleyrodidae) yüksek popülasyonlar oluşturmuştur (Ulusoy ve ark., 1996).

Türkiye'de turunçgil alanlarında geçmiş yıllarda önemli düzeyde zararlar oluşturmuş olan Turunçgil beyazsineği ilk olarak 1965'de Doğu Karadeniz Bölgesi'nde (Zoral, 1974), 1972'de Ege Bölgesi'nde (Ulu, 1985) ve 1976 yılında Doğu Akdeniz Bölgesi'nde görülmüş (Soylu ve Ürel, 1977; Özer ve Kısmalı, 2003); bu türü 1982 yılında Akdeniz Bölgesi'nde ve $1988^{\prime}$ de Ege Bölgesi turunçgil alanlarında zararları görülen Defne beyazsineği izlemiştir (Atay ve Şekeroğlu, 1987; Öncüer ve Yoldaş, 1988; Yumruktepe ve ark., 1992). Söz konusu beyazsinek türlerinin etkili doğal düşmanlarından yararlanılmış ve bu türler günümüzde entomolojik bir sorun olmaktan çıkmıştır (Ulusoy ve Uygun, 1996; Yiğit ve ark., 2003).

Samandağ (Hatay) yöresi turunçgillerinde Turunçgil pamuklu beyazsineği, Aleurothrixus floccosus (Maskell) ve Turunçgil ipek beyazsineği, Paraleyrodes minei laccarino (Hom.:Aleyrodidae) 1994 yılında tespit edilmiştir (Ulusoy ve Uygun, 1996). Bunlardan $A$. floccosus üzerinde bazı çalışmalar yapılmış olmakla birlikte (Ulusoy ve ark., 2003; Vatansever ve Ulusoy, 2004; Vatansever Sakin ve Ulusoy, 2009), P. minei üzerinde ayrıntılı çalışmalara rastlanılamamıştır. $P$. minei'nin uygun iklim şartları ve etkili doğal düşmanlarının bulunmaması durumlarında kısa sürede yüksek yoğunluklar oluşturarak gerek Hatay ili, gerekse bulaşık fidanların turunçgil yetiştirilen diğer bölgelere taşınıp yayılması ile önemli ölçüde ürün kayıplarına yol açması muhtemeldir. Öte yandan P. minei'nin etkili bir doğal düşmanı konusunda herhangi bir kayda da rastlanmamıştır.

Bu çalışma ile Hatay'da $P$. minei'nin konukçuları, turunçgil ağaçları üzerindeki dağılım durumu, popülasyon değişimleri ve biyolojisi belirlenmiştir.

\section{MATERYAL ve YÖNTEM}

\section{Paraleyrodes minei'nin konukçularının belirlenmesi}

Paraleyrodes minei'nin gerek yayılış alanları, gerekse popülasyon değişiminin belirlenmesi amacıyla yapılan örneklemeler sırasında konukçu olabilecek bitkiler incelenmiş ve üzerlerinde bu türe ait pupa veya pupa gömleği görülen bitkiler konukçu olarak kaydedilmiştir. Ayrıca doğal şartlarda konukçu olarak belirlenen bitkilerle ilgili tespitlerin laboratuvar şartlarında doğrulanması amacıyla, zararlı türün larva ve pupalarının bulunduğu çok sayıdaki yaprak, diğer zararlılar ayıklandıktan sonra ayrı ayrı plastik kavanozlar içerisine alınarak elde edilen erginler, karışık cinsiyette bir gün süreyle bir arada bekletilmiştir. Bu erginler kavanozlardan cam tüpler yardımıyla toplandıktan sonra turunç (Citrus aurantium L.), portakal (C. sinensis Osbeck), mandarin (C. reticulata Blanco), limon (C. lemon L.), altıntop (C. paradisi Macf.) (Rutaceae), patlıcan (Solanum melongenum L.), domates (Lycopersicon esculentum Mill.) (Personaiae: Solanaceae) ve Trabzon hurması (Diospyros kaki L.), (Ebenaceae) üzerine geçirilen şifon dal kafesler içerisine ayrı ayrı bırakılmış ve bu bitkilerin yapraklarında pupalar görülünceye kadar 23 gün aralıklarla stereoskopik mikroskop altında zararlının ergin öncesi dönemleri izlenmiştir.

Paraleyrodes minei'nin Hatay ilindeki yayılış alanlarını belirlemek amacıyla 2005-2006 yıllarında turunçgil yetiştiriciliği yapılan ilçelerde yaklaşık \%1,06 oranında temsili bir örnekleme yapılmış; düzenli olmayan aralıklarla turunçgil alanları ve çevresindeki bitkiler incelenerek söz konusu zararlıların yayılış alanları ortaya çıkarılmıştır.

\section{Paraleyrodes minei'nin ağaç üzerindeki dağılımı ve farklı özellikteki yaprak tercihi}

Paraleyrodes minei'nin ağaç üzerindeki dağılımı ve farklı özellikteki (genç veya olgun) yaprak tercihini belirlemek amacı ile Dörtyol'da P. minei ile bulaşık "Satsuma" çeşidi yaklaşık 15 yıllık bir mandarin bahçesinde tesadüfen seçilen 5 ağaç işaretlenmiş ve bu ağaçlardan 2005 ve 2006 yıllarında Mayıs-Ekim ayları boyunca dört örnekleme yapılmıştır. Bunun için her ağacın dört yönünden (kuzey, güney, doğu, batı) ve farklı yüksekliklerden (üst; yerden $2 \mathrm{~m}$ yükseklikte, orta; yerden $1,5 \mathrm{~m}$ yükseklikte ve alt; yerden $1 \mathrm{~m}$ yükseklikte) olmak üzere toplam 12 sürgün alınmıştır. Bu sürgünlerin genç ve olgun yaprakları uçtan itibaren ayrı ayrı numaralanarak stereoskopik mikroskopla incelenmiş; $P$. minei ile bulaşık ve bulaşık olmayan yapraklar kaydedilmiştir. Bu şekilde bu böceğin ağaç üzerinde gerek yön ve gerekse yaprak niteliği tercihleri ortaya çıkarılmıştır. Elde edilen verilerin varyans analizi SPSS 11,5 paket programına göre yapılmıştır. Böylece $P$. minei'nin ağaç üzerinde farklı yön ve yüksekliklere göre bulaşıklık oranları belirlenmiştir. 


\section{Paraleyrodes minei'nin popülasyon değişimi}

Dörtyol'da P. minei ile bulaşık, 15 yıllık "Satsuma" çeşidi bir turunçgil bahçesinde 2005 Temmuz-2006 Ağustos tarihleri arasında 2-3 hafta aralıklarla örneklemeler yapılmıştır. Bu amaçla her ağaçta tesadüfen en az 10'ar yaprakta bulunan bütün canlı bireyler (yumurta, larva, pupa) sayılmış ve popülasyon değişimleri belirlenmiştir.
Mevsim boyunca popülasyon değişimlerinin izlendiği bahçede 2005 yılı Eylül ayında, fumajin oluşumuna sebep olan öteki zararlı türler yönünden bulaşık olmayan ve $P$. minei için seçilen 50'şer ağaçta Ulu (1984)'ya göre hazırlanan aşağıdaki skalaya göre fumajin oluşum düzeyleri kaydedilmiştir (Çizelge 1).

Çizelge 1. Paraleyrodes minei laccarino örneklemesi yapılan turunçgil ağaçlarında fumajin oluşum düzeyi skalası (Ulu, 1984 'dan uyarlanarak)

\begin{tabular}{ll}
\hline Ağaçların zararı ile bulaşma indeksi & Fumajin durumu \\
\hline 0 & Temiz \\
1 & Az $(+)$ \\
2 & Orta $(+)$ ya da yalnız iç kısımdaki yapraklar fumajinli \\
3 & Yoğun $(++)$ ya da bütün yaprakların \%25-50'si bulaşık \\
4 & Çok yoğun $(+++)$ ya da bütün yaprakların \%51-100'ü fumajinli \\
\hline
\end{tabular}

\section{Paraleyrodes minei'nin biyolojisi ile ilgili çalışmalar}

\section{Doğa çalışmaları}

Paraleyrodes minei'nin biyolojisinin belirlenmesi amacıyla Dörtyol'da "Satsuma" çeşidi bir mandarin bahçesinde seçilen 5 ağacın 5'er sürgününde gözlemler yapılmıştır. Bu amaçla $P$. minei erginleri şifon dal kafesleri içerisine ayrı ayrı bırakılmış, dal kafesler içerisindeki sürgünler ilkbahar-sonbahar döneminde haftada bir, kış aylarında ise 2-3 haftada bir kontrolleri yapılarak yumurta ve larvalar izlenmiş; yeni erginler aynı şekilde temiz sürgünlere şifon kafes içerisinde aktarılmıştır. Böylece bu böceğin 2005-2006 yıllarında biyolojik gelişme dönemlerine ait başlangıç ve sona erme tarihleri ile yılda verdiği döl sayısı belirlenmiştir.

\section{Laboratuvar çalışmaları}

Paraleyrodes minei'nin laboratuvar şartlarında $\left(25 \pm 2^{\circ} \mathrm{C}\right.$ sıcaklık, \%70-80 orantılı nem ve günde 16 saat aydınlık) biyolojilerinin belirlenmesi amacıyla saksılarda yetiştirilmiş "Satsuma" çeşidi mandarin fidanları kullanılmıştır. Doğadan üzerinde $P$. minei'nin karışık biyolojik dönemlerinin (larva+pupa) bulunduğu yapraklar toplanarak laboratuvara getirilmiş, diğer zararlı türler ayıklandıktan sonra plastik kavanozlar içerisine alınmış ve buradan ergin çıkışları izlenmiştir. Çıkan erginler karışık cinsiyette bir gün süreyle bir arada bekletildikten sonra mandarin fidanları üzerindeki şifon dal kafesleri içerisine, çiftleşen bireylerin seçilmesine dikkat edilerek 1 erkek +1 dişi olmak üzere bırakılmıştır. Bu bireyler ölünceye kadar izlenmiş; dişilerin bıraktığı yumurtalar her gün sayılarak kaydedilmiştir. Yumurtalar açılıncaya kadar takibi yapılmış ve böylece dişilerin bıraktığı yumurta sayısı ve yumurtaların açılma süresi bulunmuştur. Yumurtalar açıldıktan sonra hareketli bireylerin her biri ayrı bir yaprak üzerine aktarılmış ve bu yapraklar günde birkaç kez kontrol edilerek kendilerini tespit etmeleri izlenmek suretiyle hareketli dönemde geçirdikleri süreleri ortaya konmuştur. Bundan sonra yapraklardaki her birey günde bir kez aynı saatlerde stereo-mikroskopta incelenerek, larvaların deri değişimleri izlenmiş ve larva dönemi süreleri belirlenmiştir.

Bu çalışmalar sonunda $P$. minei'nin yumurta açılma, larva $\left(L_{1}-L_{3}\right)$ ve pupa süreleri ile erginlerin yaşam süreleri belirlenmiştir. Türün cinsiyet ayrımında, erkeklerin antenlerinin 3 segmentli ve renklerinin dişilere göre biraz daha koyu sarı, dişilerin antenlerinin ise 4 segmentli olması dikkate alınmıștır (Ulusoy ve Uygun, 1996). Çalışmalar 25'er birey üzerinden yürütülmüştür.

\section{BULGULAR ve TARTIŞMA}

\section{Paraleyrodes minei'nin konukçuları}

Sörvey çalışmaları sırasında Rutaceae familyasına bağlı $C$. aurantium , $C$. sinensis, $C$. reticulata, $C$. lemon, $C$. paradisi gibi turunçgil türlerinin $P$. minei'nin konukçusu olduğu belirlenmiştir. Ayrıca İskenderun'da defne [Laurus nobilis L. (Lauraceae)]; nar [Punica granatum L. (Punicaceae)]; patlıcan [S. melongena (Solanaceae)]; Japon gülü [Hibiscusrosa-sinensis L. (Malvales: Malvaceae)]; dut [Morus sp. (Moraceae)] ve Dörtyol'da (Payas) nar, patlıcan, Trabzon hurması ve Japon gülü'nün bu türün konukçusu olduğu belirlenmiş; söz konusu zararlının bu bitkiler üzerinde pupa dahil bütün biyolojik dönemlerine rastlanmıştır. Bu konukçular ile ilgili laboratuvar şartlarında yapılan çalışmada; $P$. minei'nin sadece turunçgiller üzerinde gelişmesini tamamladığı; yukarıda 
belirtilen diğer konukçular üzerinde ise herhangi bir gelişme göstermediği tespit edilmiştir. Bu durumun doğa ve laboratuvardaki ekolojik şartların farklı oluşundan kaynaklanabileceği değerlendirilmektedir.

Öte yandan bu ilçelerde alçak tüneller altında ve tarlada yetiştirilen domates bitkileri üzerinde yapılan incelemelerde $P$. minei ile herhangi bir bulaşıklık olmadığı gözlenmiştir. Ayrıca $P$. minei ile bulaşık ilçelerden Dörtyol'da bir koleksiyon bahçesinde yapılan örneklemede muz, fındık, incir, elma gibi kültür bitkilerinde yapılan incelemelerde bu bitkilerinde zararlının konukçusu olmadığı tespit edilmiştir. Cliement ve Vivas (1992), italya'da P. minei'nin Rutaceae familyasına bağlı bitkilerde, elma (Malus communis), defne ve seradaki domates bitkileri üzerinde bulunduğunu bildirmişlerdir.

Paraleyrodes minei'nin yayılış alanlarını belirlemek amacıyla 2005-2006 yıllarında düzenli olmayan aralıklarla turunçgil alanlarında yapılan çalışmalarda, $P$. minei'nin Hatay ilinde ortalama \%4,93 oranında yaygınlık gösterdiği belirlenmiştir. $P$. minei'nin Hatay'da turunçgil yetiştiriciliğinin yoğun olarak yapıldığı İskenderun, Dörtyol ve Samandağ ilçelerinde var olduğu görülmüş; bu yörelerden de en yaygın olarak İskenderun'da bulunduğu belirlenmiştir.

\section{Paraleyrodes minei'nin ağaç üzerindeki dağılımı ve farklı özellikteki yaprak tercihi}

Paraleyrodes minei'nin ağaç üzerindeki farklı konumlardaki bulaşıklık oranlarının karşılaştırılması için yapılan değerlendirmelerde, söz konusu beyazsinek türünün ağacın gerek yön ve gerekse tacın üst, orta ve alt bölümlerindeki bulaşıklık oranlarının istatistikî olarak önemli olmadığı $(p<0.05)$ ortaya konmuştur (Şekil 1 ve 2 ). Buna göre yapılacak sörvey çalışmalarında ağaçların her yönünden ve her yüksekliğinden örneklemelerin yapılabileceği kanısına varılmıştır.
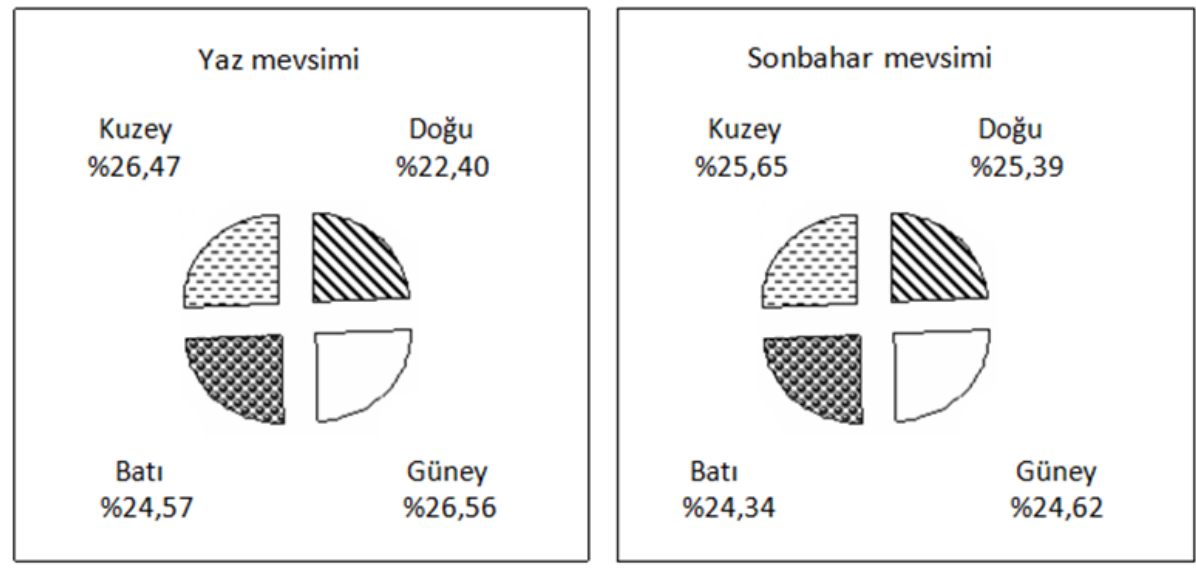

Şekil 1. Dörtyol (Hatay)'da 'Satsuma' çeşidi bir mandarin bahçesinde 2005-2006 yılları arasında yaz ve sonbahar mevsimlerinde Turunçgil ipek beyazsineği, Paraleyrodes minei laccarino'nin ağacın yöneylerine göre bulaşıklık oranları (\%)
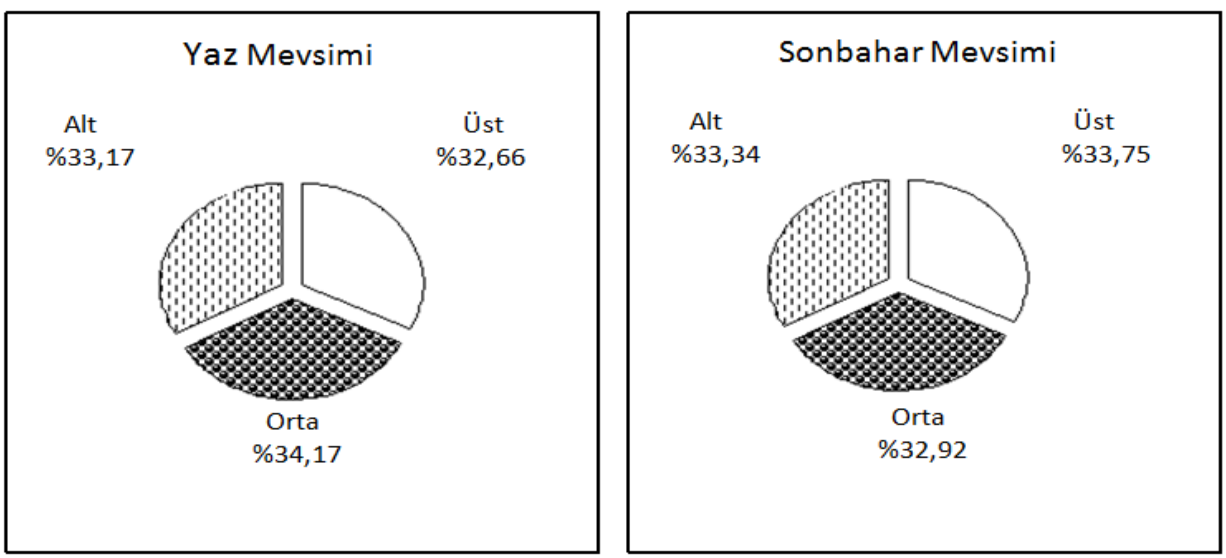

Şekil 2. Dörtyol (Hatay)'da 'Satsuma' çeşidi bir mandarin bahçesinde 2005-2006 yılları arasında yaz ve sonbahar mevsimlerinde Turunçgil ipek beyazsineği, Paraleyrodes minei laccarino'nin bir ağacın taç düzeylerine göre bulaşıklık oranları (\%) 
Paraleyrodes minei'nin turunçgil ağaçlarında mevsim, yön, yükseklik ve bunların interaksiyonları ile ilgili sonuçları üzerinde yapılan istatistiki değerlendirmelere göre, yaz ve sonbahar mevsimlerinin, taç içindeki yön ve yükseklik farkının önemli olmadığı belirlenmiştir. Bu beyazsineğin sörveyinde mevsim ve ağaç içindeki yön ve yükseklik farklııklarına bakılmaksızın örnekleme yapılabileceği kanaatine varılmıştır (Şekil 1 ve 2).

Paraleyrodes minei'nin turunçgil ağaçlarında farklı özellikteki yaprak tercihi ile ilgili yapılan çalışmalar sonucunda, her iki mevsimde de özellikle olgun yapraklardaki $P$. minei popülasyonu taze yapraklara oranla daha yüksek bulunmuş; mevsim ve yaprak yaşının birlikte etkileşiminin zararlının dağılımında etkili olduğu belirlenmiştir ( $\mathrm{Bu}$ tercih istatistiki olarak da ortaya konmuştur) (F:37,428; df:1,192; $\mathrm{p}=0,000)$. P. minei erginlerinin yaz aylarında ortaya çıkması ile beraber, popülasyonun taze sürgünlerin gelişmesini tamamlamış olgun yapraklarında görüldüğü ve olgun sürgünlerde bir yıllık yapraklarda bulaşıklık oranının yüksek olduğu belirlenmiştir. Diğer bir ifade ile zararlının taze sürgünler üzerinde bulunan ve gelişmekte olan körpe yaprakları tercih etmediği görülmüştür. Ayrıca bu zararlının doğada tespit edilen konukçularından Citrus türlerinin laboratuvar şartlarında doğrulanması amacıyla yapılan çalışmalar sırasında, şifon kafesler içerisindeki turunçgil türleri üzerine bırakılan $P$. minei erginlerinin sadece olgun yapraklar üzerinde yumurta bırakıp geliştikleri gözlenmiştir.

Paraleyrodes minei'nin sörveyinde olgun yaprakların kontrol edilmesi gerektiği daha önce yapılan bazı çalışmalarda da bildirilmiştir (Cliement ve Vivas, 1992; Ulusoy ve Uygun, 1996).

\section{Paraleyrodes minei'nin popülasyon değişimi}

Paraleyrodes minei'nin Dörtyol (Hatay)'da 2005-2006 yıllarına ait popülasyon dalgalanmaları ile ilgili sonuçlar Şekil 3'te verilmiştir.

Paraleyrodes minei için beş avcı tür, Cunaxa potchensis Den Heyer (Acari: Cunaxidae), Clitostethus arcuatus
Risso, Chilocorus bipustulatus L. (Coleoptera: Coccinellidae), Conwentzia sp., Chrysoperla carnea Stephens (Neuroptera: Chrysopidae) tespit edilmiş; bu zararlıyı ayrıca Encarsia hispida DeSantis (Hymenoptera: Aphelinidae)'nın parazitlediği ortaya konmuştur. E. hispida'nın P. minei'yi parazitleme oranının 2005-2006 yıllarında en yüksek \%38,73 olduğu belirlenmiştir. Ayrıca entomopatojen fungus, Cladosporium sp. (Moniliales: Dematiaceae)'un doğada P.minei kolonilerinde geliştiği görülmüştür (Telli ve Yiğit, 2012).

Paraleyrodes minei'nin popülasyon takibine 2005 yılının Ağustos ayında başlanmış olup ilk yapılan sayımlarda yaprak başına 18 adet yumurta, 5 adet larva ve pupa ile 0,1 adet pupa kabuğu sayılmıştır. Bu tarihten sonra pupadan ergin çıkışlarının artmasıyla birlikte yumurta sayısında da belirgin artış olmuş ve Eylül başında tepe noktasına ulaşmıştır. Yumurta artışına paralel olarak larva dönemlerinde de bir artış olmuş ve bu tarihten sonra popülasyon giderek bir düşüş göstermiştir. Zararlı kış aylarında da aktif olarak gelişmesini sürdürmüş ve 2006 yılı Ocak ayı sonunda gerek yumurta sayısında ve gerekse larva dönemlerinde düşük oranda da olsa ikinci bir tepe noktası görülmüştür (Şekil 3).

Paraleyrodes minei'nin erginleri 2006 yılında ve Haziran ayının ilk yarısında görülmüştür. Şekil 3 incelendiğinde, zararlının temmuz ayının ilk haftasında yumurta yoğunluğunun artmaya başladığı, bunu takiben larva ve pupa sayısının da yumurta kadar yoğun olmasa bile yine artış içinde olduğu görülmektedir. Yumurta sayısı fazla olmasına rağmen, süregelen larva ve ergin yoğunluklarında bir azalma görülmektedir. Bunun en büyük sebebinin, belirlenen doğal düşmanlardan özellikle $C$. arcuatus, Conwentzia spp., $C$. carnea ve $C$. bipustulatus'un söz konusu zararlının yumurta ve larvalarıyla beslenmesinden kaynaklandığı söylenebilir. Çalışmaların yapıldığı yıllarda $P$. minei popülasyonunun artışı ile beraber, takip eden dönemlerde doğal düşman yoğunluklarının artmasıyla, bu beyazsineğin doğal düşmanlarca baskı altına alındığı görülmektedir. 


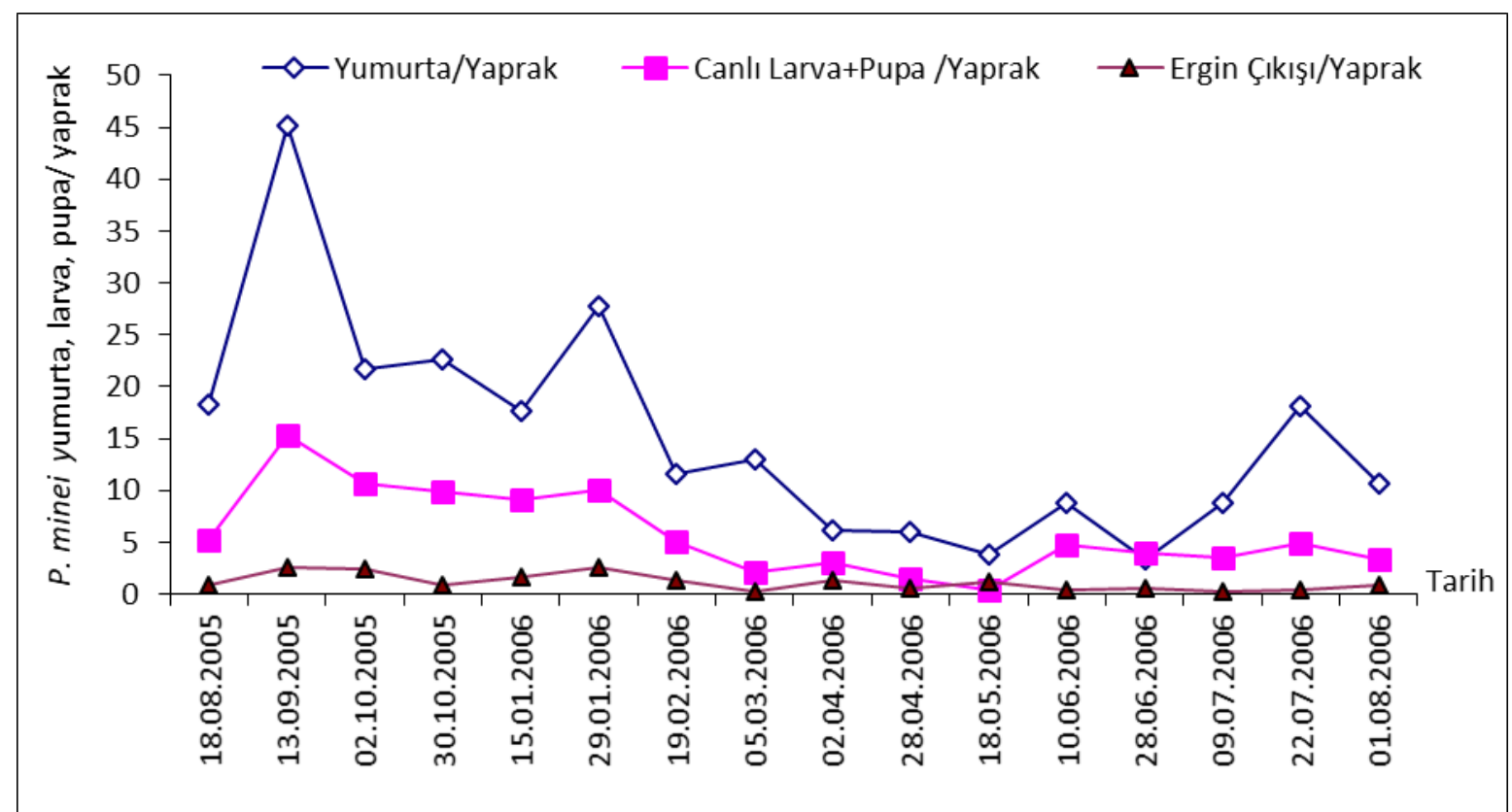

Şekil 3. Dörtyol (Hatay)'da 2005-2006 yıllarında "Satsuma" çeşidi bir mandarin bahçesinde Turunçgil ipek beyazsineği, Paraleyrodes minei'nin popülasyon değişimi

En düşük popülasyon yoğunluğu Mart, Nisan ve Mayıs aylarında olup, Eylül ayı ile birlikte $P$. minei yumurta yoğunluğu ile beraber, larva ve pupa popülasyon yoğunluğu da artmakta, kış aylarında ergin çıkışları dahi görülmektedir. Dolayısıyla zararlının kışı her gelişme döneminde geçirdiği söylenebilir.

Paraleyrodes minei'nin popülasyon değişiminin izlendiği bahçede fumajinlenme düzeyleri de tespit edilmiştir. $P$. minei'nin önemli bir fumajin oluşturmadığı, ağaçların çok az bir kısmında düşük düzeyde (Bulaşma indeksi ortalama 0,46) bir fumajin zararı meydana getirdiği görülmektedir. Buna göre söz konusu zararlı beslenme zararı dışında fumajin oluşumu bakımından önem taşımadığı söylenebilir.

\section{Paraleyrodes minei'nin biyolojisi}

Paraleyrodes minei dişileri yumurtalarını olgun yaprakların alt yüzeylerine uzun bir sapçık yardımıyla tek tek bırakır. Ilk bırakılan yumurtalar beyaz renktedir; açılmaya yakın koyulaşarak morumsu bir renge dönüşür. Bu türün bireyleri yumurta bırakmak veya beslenmek için yaprak alt yüzeyinde belirli bir yer seçimi yapmamaktadır. Birinci larva dönemi mat sarı renklidir. íkinci dönem larva parlak sarı renkte olup; üzerinde ipeğimsi, yanlarda ise kısa ipeksi salgıların gelişimi başlamaktadır. Üçüncü dönem larva üzerinde ipeğimsi salgı oranı giderek artmaktadır. Dördüncü dönem larva tamamen ipeğimsi salgı ile örtülmekte ve bir çift petek göz belirgin hal almaktadır. Bu böceğin pupası, üzerinde pamuğumsu ve balımsı madde olmadığı için, daha belirgin olarak görülmektedir. P. minei'nin larva ve pupaları üzerinde dik olarak 12 adet iplikçik çıkmaktadır. Gerek dişi, gerekse erkek erginlerin çok yavaş hareket ettiği ve yaprağın alt yüzeyinde beslendikleri gözlenmiştir (Şekil 4). P. minei erginlerinin yaprak üzerinde tek tek bulundukları, bir yaprak üzerinde zararlının ergin dâhil olmak üzere bütün dönemlerinin bir arada bulunabildiği tespit edilmiştir. Nitekim Cliement ve Vivas (1992) ile Özger (2014)'de yukarıda açıkladığımız bilgileri teyit edecek nitelikte bilgiler vermiştir. Öte yandan Soto ve Mari (2000), Turunçgil ipek beyazsineği dişilerinin yumurtalarını yapraklara daire şeklinde yerleştirdiğini; Anonim (2001), söz konusu zararlının yumurta ve erginlerinin soluk sarı renkte olduğunu, yumurtaların erginler tarafından tüy gibi yumuşak bir mumla sarıldığını, pupanın da geniş mum şeritleriyle saçaklandığını ve diğer bazı zararlı türlerle karışık olarak bir arada bulunabileceğini bildirmiştir. 


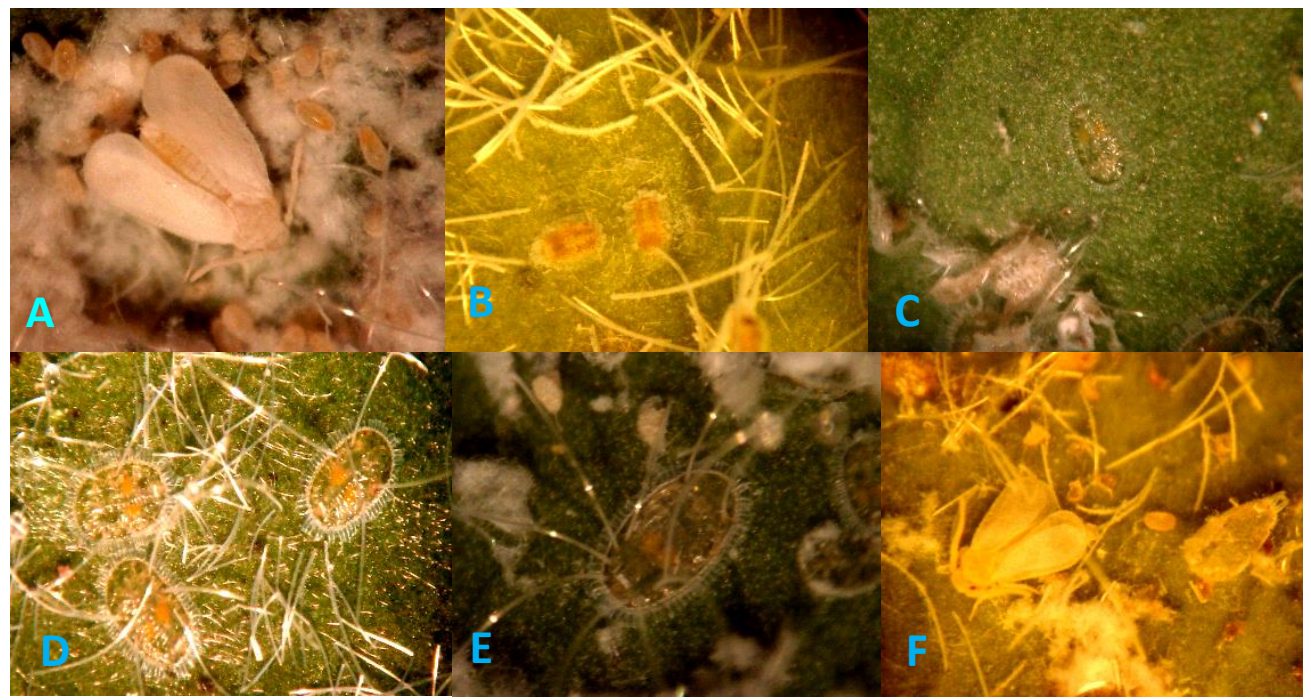

Şekil 4. Turunçgi lipek beyazsineği, Paraleyrodes minei laccarino'nin biyolojik gelişme dönemleri (A-Ergin $P$. minei ve yumurtalar, B-Hareketli 1. dönem larvalar, C-2. dönem larva, D-3. dönem larva, E-4. dönem larva+pupa, F-Ergin $P$. minei ve pupa gömleği)

\section{Doğa çalış̧maları}

Dörtyol'da 2005-2006 yıllarında P. minei'nin ilk erginleri şifon dal kafesler içerisinde, 18.8.2005 tarihinde kültüre alınmıştır. P. minei'nin Dörtyol (Hatay)'da yılda 8 döl verdiği belirlenmiştir (Şekil 5).

Paraleyrodes minei'nin kış aylarında bütün gelişme dönemlerinin bir arada bulunabildiği ve gelişmelerini sürdürdükleri tespit edilmiştir. Çalışmalar sonucunda, bir dişinin ortalama 28,08 yumurta bıraktığı ve yumurta açılma süresinin ortalama 8,12 gün olduğu bulunmuştur. Bu türün birinci dönem larva süresinin 5,32 gün, ikinci dönem larva süresinin 5,52 gün, üçüncü dönem larva süresinin 2,60 gün, dördüncü dönem larva ve/veya pupa süresinin 8,40 gün olduğu, bir dölünü 2005 yılı AğustosEylül ayları arasında ve doğa şartlarında Dörtyol (Hatay)'da ortalama 29,96 günde tamamladığı belirlenmiştir.

\section{Laboratuvar çalışmaları}

Laboratuvarda yapılan çalışmalarda, $P$. minei dişi bireylerinin ortalama 25,12 adet yumurta bıraktığı, yumurta açılma süresinin ortalama 6,64 gün olduğu belirlenmiştir. Yumurtadan çıkan larvaların ortalama 5,12 (1-8) saat gezinerek kendilerini yaprağın alt yüzeyine sabitlediği belirlenmiştir. Birinci dönem larva süresinin ortalama 4,96 gün, ikinci dönem larva süresinin 5,08 gün, üçüncü dönem larva süresinin 2,48 gün, dördüncü dönem larva ve/veya pupa süresinin de 7,12 gün olduğu ve $P$. minei'nin bir dölünü ortalama 26,28 günde tamamladığı tespit edilmiştir. Ergin dişinin ortalama 9,04 gün; ergin erkeğin ise ortalama 4,16 gün yaşadığı belirlenmiştir. Cliement ve Vivas (1992)'da İspanya'da laboratuvar şartlarında $P$. minei'nin bir dölünü 3 haftada tamamladığını bildirmektedir.

Sonuç olarak $P$. minei'nin uygun iklim şartlarında ve etkili doğal düşmanlarının bulunmaması durumunda, yüksek yoğunluklara ulaşabilecek ve turunçgillerde önemli konuma geçebilecek bir zararlı potansiyelinde olduğu düşünülmektedir. Bu nedenle zararlıya ait doğal düşman türlerinin doğada varlığını sürdürebilmesi ve etkinliklerinin artırıması amacı ile entegre savaş yaklaşımı içerisinde gerekli uygulamaların yapılması yararlı olacaktır. 


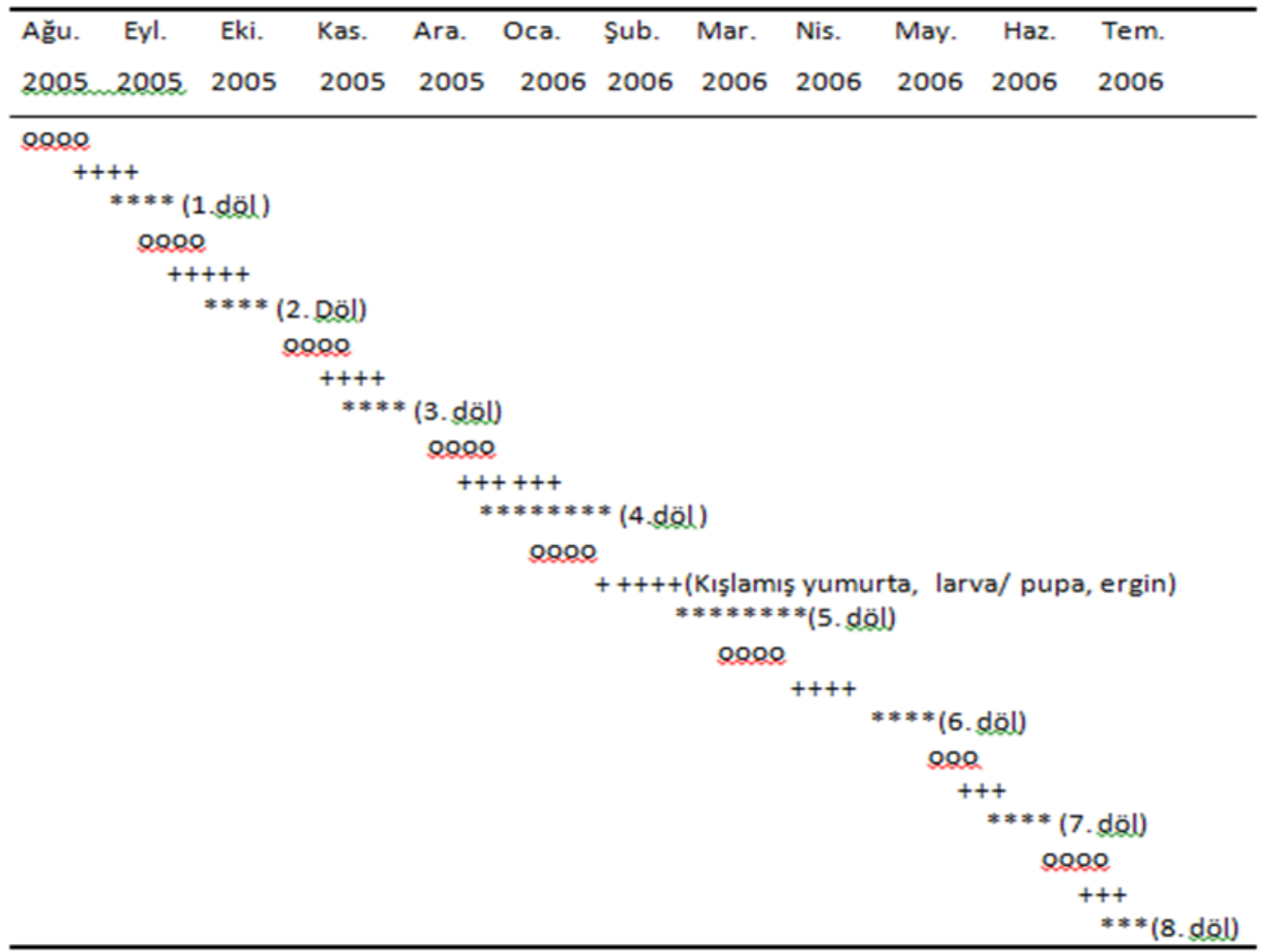

Şekil 5. Dörtyol (Hatay)'da 2005-2006 yıllarında doğal şartlarda Turunçgil ipek beyazsineği, Paraleyrodes minei laccarino'un yaşam döngüsü (oooo Yumurta, ++++ Larva ve/veya pupa, **** Ergin)

\section{ÖZET}

Amaç: Hatay'da 2005-2006 yıllarında yürütülen çalışmada turunçgillerde görülen Turunçgil ipek beyazsineği, Paraleyrodes minei laccarino (Hemiptera: Aleyrodidae)'nin konukçuları, popülasyon değişimleri ve biyolojisi belirlenmiştir.

Yöntem ve Bulgular: Paraleyrodes minei'nin konukçusu olabilecek bitkilerde söz konusu zararının pupa ve pupa gömleği aranmıştır. Popülasyon değişimi çalışması için Dörtyol (Hatay)'da 2005-2006 yıllarında en az 15 yıllık "Satsuma" çeşidi mandarin bahçesinde tesadüfi 5 ağacın 5'er sürgününde gözlemler yapılmış; biyolojisiyle ilgili çalışmalar doğada ve laboratuvarda 25 birey üzerinden yürütülmüştür.

2005-2006 yıllarında Hatay'ın Samandağ, Dörtyol ve İskenderun ilçelerinin $P$. minei ile bulaşık olduğu anlaşıımıştır. Turunçgiller dışında $P$. minei'nin konukçularının, patlıcan (Solanum melongena L.), defne (Laurus nobilis L.), nar (Punica granatum L.), hurma (Diospyros kaki L.), Japon gülü (Hibiscus rosa-sinensis L.) ve dut (Morus sp.) olduğu belirlenmiştir.

Beyazsineğin sörveyinde mevsim ve ağaç içindeki yön ve yükseklik farklılıklarına bakılmaksızın örnekleme yapılabileceği kanaatine varılmıştır. $P$. minei larva ve pupa popülasyonlarının Temmuz ayı başlarında yükseldiği, daha sonra doğal düşman türleri, Conwentzia sp., Chrysoperla carnea Stephens (Neuroptera: Chrysopidae), Encarsia hispida DeSantis (Hymenoptera: Aphelinidae), Clitostethus arcuatus Risso, Chilocorus bipustulatus L. (Coleoptera: Coccinellidae) ve entomopatojen fungus, Cladosporium sp. (Moniliales: Dematiaceae)'un faaliyetleri sonucu yoğunluğun düştüğü görülmüştür. P.minei'nin doğada yılda 8 döl verdiği belirlenmiştir. Laboratuvar şartlarında $\left(25 \pm 2^{\circ} \mathrm{C}\right.$ sıcaklık, \%70-80 orantılı nem ve günde 16 saat aydınlık) ve doğada yumurtadan ergin oluncaya kadar gelişme süresi sırasıyla ortalama 27,88 (24-29) gün ve 29,96 (2735) gün olarak bulunmuştur.

Genel Yorum: Paraleyrodes minei'nin yayılabileceği, turunçgiller dışında konukçularının olduğu, turunçgil ağacının her tarafında bulunabileceği, olgun turunçgil yapraklarında yüksek yoğunluklar oluşturduğu belirlenmiştir.

Söz konusu zararlının doğal düşmanlarca baskı altına alınabileceği ortaya konmuştur.

Çalışmanın Önemi ve Etkisi: Paraleyrodes minei'nin uygun iklim şartlarında ve etkili doğal düşmanlarının bulunmaması durumunda, yüksek yoğunluklara ulaşabilecek ve turunçgillerde önemli konuma 
geçebilecek bir zararlı potansiyelinde olduğu düşünülmektedir. Bu nedenle zararlının doğal düşman türlerinin turunçgil ekosisteminde varlığını sürdürebilmesi ve etkinliklerinin artırılması amacıyla entegre savaş yaklaşımı içerisinde gerekli uygulamaların yapılması yararlı olacaktır.

Anahtar Kelimeler: Turunçgil ipek beyazsineği, Paraleyrodes minei, Türkiye, turunçgil.

\section{ÇIKAR ÇATIŞMA BEYANI}

Yazar(lar) çalışma konusunda çıkar çatışmasının olmadığını beyan eder.

\section{ARAŞTIRMACILARIN KATKI ORANI BEYANI}

Yazarlar çalışmaya eşit oranda katkı sağlamış olduklarını beyan eder.

\section{KAYNAKLAR}

Anonim (2001) Paraleyrodes minei laccarino http://www.padil.gov.au/pests-anddiseases/pest/main/136088/8649 Tarihi:25.07.2018)

Atay S, Şekeroğlu E (1987) Defne beyazsineği, Parabemisia myricae Kuwana (Homoptera: Aleyrodidae)'nin farklı turunçgil türleri üzerinde populasyon dalgalanması. Türkiye 1. Entomoloji Kongresi Bildirileri 13-16 Ekim, İzmir, 59-67.

Cliement JML, Vivas AG (1992) Homoptera III. Moscas Blancas Y Su Control Biologica, Pisa Ediciones, Italia. pp 204.

Mound LA, Halsey SH (1978) Whitefly of the World. A Systematic Catalogue of the Aleyrodidae (Homoptera) With Host Plant and Natural Enemy Data. British Museum (Natural History) and John Wiley and Sons, Chicester-New York- Brisbanbe, Toronto. pp 340.

Öncüer C, Yoldaş Z (1988) İzmir ili turunçgil bahçelerinde yeni bir zararlı: Parabemisia myricae (Hom: Aleyrodidae). Türk. Entomol. Derg. 12(4): 231-233.

Özer G, Kısmalı Ş (2003) İzmir ili turunçgil alanlarında Turunçgil pamuklu beyazsineği Aleurothrixus floccosus (Maskell) (Homoptera: Aleyrodidae)'un yayılışı, zarar ve populasyon yoğunluğu üzerinde araştırmalar. Türk. Entomol. Derg. 27(1): 61-72.

Özger Ş (2014) Antalya ili Turunçgillerinde Beyazsinek (Hemiptera: Aleyrodidae) Türleri, Yayılışları, Doğal Düşmanları ile Önemli Türlerin Popülasyon Gelişmeleri. Doktora Tezi, Süleyman Demirel Üniversitesi, Fen Bil. Ens., Bitki Koruma ABD, 124 s.
Soto A, Mari FG (2000) Species of whiteflies in citruses of peninsular Spain. The whiteflies of citrus. Andnero. http://www.seea.es/conlupa/mbcitricos/mbCitricos 4.htm (Erişim Tarihi:16.10.2005)

Soylu OZ, Ürel N (1977) Güney Anadolu bölgesi turunçgillerinde zararlı böceklerin parazit ve predatörlerinin tesbiti üzerinde araştırmalar. Bitki Koruma Bülteni 17(2-4): 77-112.

Telli Ö, Yiğit A (2012) Hatay ili turunçgillerinde zararlı Turunçgil pamuklu beyazsineği, Aleurothrixus floccosus (Maskell) ve Turunçgil ipek beyazsineği, Paraleyrodes minei laccarino (Hemiptera: Aleyrodidae)'nin doğal düşmanları. Türk. Entomol. Derg. 36(1): 131-138.

Ulu O (1984) Ege Bölgesi Turunçgillerinde Zararlı Dialeurodes citri (Ashmead) (Hom.: Aleyrodidae)'nin Tanınması, Zararı, Biyolojisi ve Ekolojisi ile Savaş Olanakları Üzerine Araştırmalar. Bölge Zirai Mücadele Araştırma Enstitüsü, Bornova-izmir (Yayınlanmamış Doktora Tezi), $281 \mathrm{~s}$.

Ulu O (1985) Ege Bölgesi turunçgillerinde zararlı olan Dialeurodes citri (Ashmead) (Homoptera: Aleyrodidae)'nin tanınması, zararı, biyolojisi ve ekolojisi ile savaş olanakları üzerinde araştırmalar. Ege Üniv. Zir. Fak. Derg. 22(3): 159-174.

Ulusoy MR, Uygun N (1996) Doğu Akdeniz Bölgesi turunçgillerinde potansiyel iki yeni zararlı, Aleurothrixus floccosus (Maskell) ve Paraleyrodes minei laccarino (Hom.:Aleyrodidae). Türk. Entomol. Derg. 20(2): 113-121.

Ulusoy MR, Uygun N, Kersting U, Karaca I, Satar S (1996) Present status of Citrus whiteflies (Homoptera: Aleyrodidae) in Turkey and their control. Zeitschrift für Pflanzenkrankheiten und Pflanzenschutz / Journal of Plant Diseases and Protection 103(4): 397-402

Ulusoy MR, Vatansever G, Erkiliç L, Uygun N (2003) Studies on Aleurothrixus floccosus (Maskell) (Homoptera, Aleyrodidae) and its parasitoid, Cales noacki Howard (Hymenoptera, Aphelinidae) in the East Mediterranean Region of Turkey. Anz. Scha"dlingskunde/J. PestScience 76: 163-169.

Vatansever G, Ulusoy MR (2004) Farklı sıcaklıkların Aleurothrixus floccosus (Mask.) (Homoptera: Aleyrodidae)'un bazı biyolojik özellikleri üzerine etkisi. Türkiye I. Bitki Koruma Kongresi Bildirileri 8-10 Eylül, Samsun, s 103.

Vatansever Sakin G, Ulusoy R (2009) The effects of different temperatures and diets on thebiology of Cales noacki Howard (Hymenoptera: Aphelinidae), a parasitoid of the citrus woolly whitefly. Turk. J. Agric. For. 33: 267-275. 
Yigit A, Canhilal R, Ekmekci U (2003) Seasonal population fluctuations of Serangium parcesetosum (Coleoptera: Coccinellidae), a predatory of Citrus whitefly, Dialeurodes citri (Homoptera: Aleyrodidae) in Turkey's Eastern Mediterranean citrus groves. Environ. Entomol. 32(5): 1105-1114.

Yumruktepe R, Yiğit A, Aytaş M (1992) Japon defne beyazsineği, Parabemisia myricae (Kuwana) (Homoptera: Aleyrodidae)'nin bazı biyolojik özellikleri üzerinde araştırmalar. Türk. Entomol. Derg. 16(3): 147-153.
Zoral A (1974) Doğu Karadeniz Bölgesi'nde Turunçgil Beyazsineği, Dialeurodes citri (Ashmead) (Hom.:Aleyrodidae)'nin Biyo-ekolojisi ve Savaş Metotları Üzerinde Araştırmalar. Zirai Mücadele Araştırma Enstitüsü, Samsun (Uzmanlık Tezi, Yayınlanmamış), $72 \mathrm{~s}$. 